\title{
A Novel Synthetic Route to Fatty Amides in Non-aqueous Reaction of Fatty Esters with Ammonium Salts and Methyl Amine
}

\author{
Onyanobi Abel-Anyebe ${ }^{1}$, K. I. Ekpenyong ${ }^{2}$ \& Anthonia Eseyin ${ }^{2}$ \\ ${ }^{1}$ Science Laboratory Technology Department, Benue State Polytechnic, Ugbokolo, Nigeria \\ ${ }^{2}$ Department of Chemistry, University of Jos, Jos, Nigeria \\ Correspondence: Onyanobi Abel-Anyebe, Science Laboratory Technology Department, Benue State Polytechnic, \\ Ugbokolo, Nigeria. Tel: 234-706-494-8786. E-mail: onyanobi@yahoo.com
}

\author{
Received: August 7, 2012 Accepted: October 29, 2012 Online Published: January 24, 2013 \\ doi:10.5539/ijc.v5n1p80 URL: http://dx.doi.org/10.5539/ijc.v5n1p80
}

\begin{abstract}
Fatty amides have been widely produced by the reaction of ammonia and amines with fatty acids. Fatty amide formation from fatty esters (i.e. the ester-ammonia route) is not widely applied because it does not have much practical value. There are no reported cases of these fatty esters being used directly in amide production. When, however, a fatty ester is to be employed in the production of an amide, the ester is first stripped to the fatty acid. The methods of synthesis employing even the simple esters require in most cases harsh reaction conditions. In this work, a fatty ester (groundnut oil) was hydrolyzed using sodium hydroxide in acetone and reacted in-situ with ammonium chloride and methyl amine at $50{ }^{\circ} \mathrm{C}$. Conversions of more than $80 \%$ were obtained in a reaction time of 60 minutes beyond which the reaction attained equilibrium with reversal to starting material. IR, GC/MS and GC-FID analyses of the product samples revealed the presence of amides, ammonium salts, simple as well as mixed anhydrides of fatty acids.
\end{abstract}

Keywords: fatty acid, fatty ester, reactivity in fatty amide formation

\section{Introduction}

Fatty amides are commercially very significant and they have a wide range of applications, which is dependent upon the physical properties of the amide or in some instances, of a substance derived from the amide. Physical properties are a function of molecular structure; therefore, the various classes of amides find widely differing uses. They are used in the textile, plastic, cosmetic, paper and many other industries. Medicinally, they are used as anti-convulsants, anti-hypertensive agents and in the treatment of tuberculosis (Anyebe \& Ekpenyong, 2007). It is now well established that fatty acyl amides modulate several physiological processes, including pain sensitivity, reproduction, immune function and vascular tone among others (Christie, 2007a; Hanus, Gopher, Almong, \& Mechoulam, 1993; Kunos, Varga, Wagner, Ellis, \& Sanyai, 1999; Anonymous, 1999).

Different methods have been used in the synthesis of fatty amides. The most common are those involving the reaction between ammonia and amines with fatty acids:

$$
\begin{array}{ll}
\mathrm{RCOOH}+\mathrm{NH}_{3} & \mathrm{RCONH}_{2}+\mathrm{H}_{2} \mathrm{O} \\
\mathrm{RCOOH}+\mathrm{RNH}_{2} & \mathrm{RCONHR}+\mathrm{H}_{2} \mathrm{O}
\end{array}
$$

The ester-ammonia route is not widely applied because it does not have much practical value; apart from yielding products in trace amounts, the method requires harsh reaction conditions such as high temperatures $\left(100-220{ }^{\circ} \mathrm{C}\right.$ ), long reaction times of 3-48 hours and the use of catalysts (Anyebe \& Ekpenyong, 2007). Fatty amides may not have been produced directly from fatty oils, which are a major source of the fatty acids and these oils are available in abundance.

In this work, groundnut oil, a long chain fatty ester (glyceride) derived from glycerol and a group of fatty acids, namely: oleic $(60 \%)$, linoleic $(21 \%)$, palmitic $(7 \%)$, stearic $(5 \%)$ and others $(7 \%)$ (Ophardt, 2003) was reacted with an ammonium salt in place of ammonia. Zradni, Texier-Boullet and Hamelin (2002) studied the synthesis of amides from simple short-chain esters $\left(\mathrm{C}_{4}-\mathrm{C}_{10}\right)$ and formamide using microwave irradiation at various temperatures $\left(71-219^{\circ} \mathrm{C}\right)$ and reported the superiority of microwave irradiation over classical heating methods in the production of amides from simple esters, showing product yield of the latter method to be in trace amounts. Apart from the characterization and identification of products, this study is aimed at testing the performance of 
the heating method.

\section{Materials and Method}

The reagents consisted of groundnut oil (produced by Grand Cereal Manufacturing Company, Jos-Nigeria) which is readily available and affordable; acetone, sodium hydroxide, ammonium chloride, methyl amine, and sodium chloride. All reagents were of analytical grade.

A round-bottom flask was charged with $3.84 \mathrm{~g}$ groundnut oil and heated to $50{ }^{\circ} \mathrm{C} .15 \mathrm{~mL}$ acetone was introduced and the temperature was left to stabilize, after which $0.5 \mathrm{~g}$ finely crushed sodium hydroxide was added. The system was well clamped and heated under reflux for 10mins. Ammonium chloride was introduced and reacted in-situ at various time intervals (continuous stirring was ensured and water was excluded from the system). According to Christie (2007b) and Liberles (1968) the base-hydrolysis of an ester in the absence of water produces the carboxylate ion of the acid, while in the presence of water the corresponding acid will be the result and acids do not readily undergo hydrolysis.

At the end of each run, the reactor was cooled in a water bath and the reaction mixture was shaken with $70 \mathrm{~mL}$ $0.5 \mathrm{M}$ aqueous $\mathrm{NaCl}$ to salt-out the solid product and extract any un-reacted $\mathrm{NaOH}$, ammonium salt and glycerol that may have formed. The solid product was washed in acetone and dried at $35{ }^{\circ} \mathrm{C}$. The acetone filtrate was evaporated for the determination of the weight of the un-reacted oil.

The above reaction was carried out using methyl amine as a substitute for ammonium chloride and reacted with the oil in the same way.

The products obtained were subjected to IR, GC/MS and GC-FID analyses (IR result for only one of the products has been received).

\subsection{Esterification of Product Samples}

Product samples were saponified using methanolic $\mathrm{NaOH}$ to liberate fatty acids. These fatty acids were then esterified in the presence of methanolic $\mathrm{BF}_{3}$ catalyst to produce fatty acid methyl esters, which are volatile and therefore amenable to analysis by GC-FID using a polar capillary column (National Agency for Food and Drug Administration and Control, NAFDAC, 2007).

\section{Results and Discussion}

Solid products were obtained from the reactions. Sample 1-[Oil $+\mathrm{NH}_{4} \mathrm{Cl}$ product] is creamy and granular (melting point $184-186{ }^{\circ} \mathrm{C}$ ). It is insoluble in cold water but sparingly soluble in hot water, chloroform and benzene. It dissolved completely in chloroform/water and benzene/water mixtures to produce a whitish suspension. The aqueous suspension was found to be basic. On boiling the sample in aqueous sodium hydroxide solution, ammonia gas was released. This is a known test for ammonium salts and amides (Holderness, 1970).

Sample 2-[Oil $\left.+\mathrm{CH}_{3} \mathrm{NH}_{2}\right]$ is brownish, granular (melting point $194-196{ }^{\circ} \mathrm{C}$ ) and exhibited similar solubility properties as Sample 1.

Wikipedia encyclopedia described oleamide, (9-octadecenamide), a derivative of the most abundant fatty acid found in groundnut oil, as a creamy solid in appearance. This description fits the appearance of Sample 1.

Numerous peaks in the gas chromatograms of the product samples should be an indication of their heterogeneous nature.

Absorption bands appearing at 3471.80 and $3339.68 \mathrm{~cm}^{-1}$ in the IR spectrum of Sample 1 (Figure 1) are very significant. This region of absorption is characteristic of N-H stretching and the separation of about $131 \mathrm{~cm}^{-1}$ between these two bands falls within the range of $120-180 \mathrm{~cm}^{-1}$, which is exhibited typically by primary amides in solid state spectra. This is strongly indicative of the presence of either $-\mathrm{NH}_{2}$ or $-\mathrm{NH}_{4}$ groups (or both) in the product. Equally significant is the strong absorption at $1743.38 \mathrm{~cm}^{-1}$ which is associated with the stretching vibration of the $\mathrm{CO}$ bond present in all classes of amides (Kemp, 1987). 


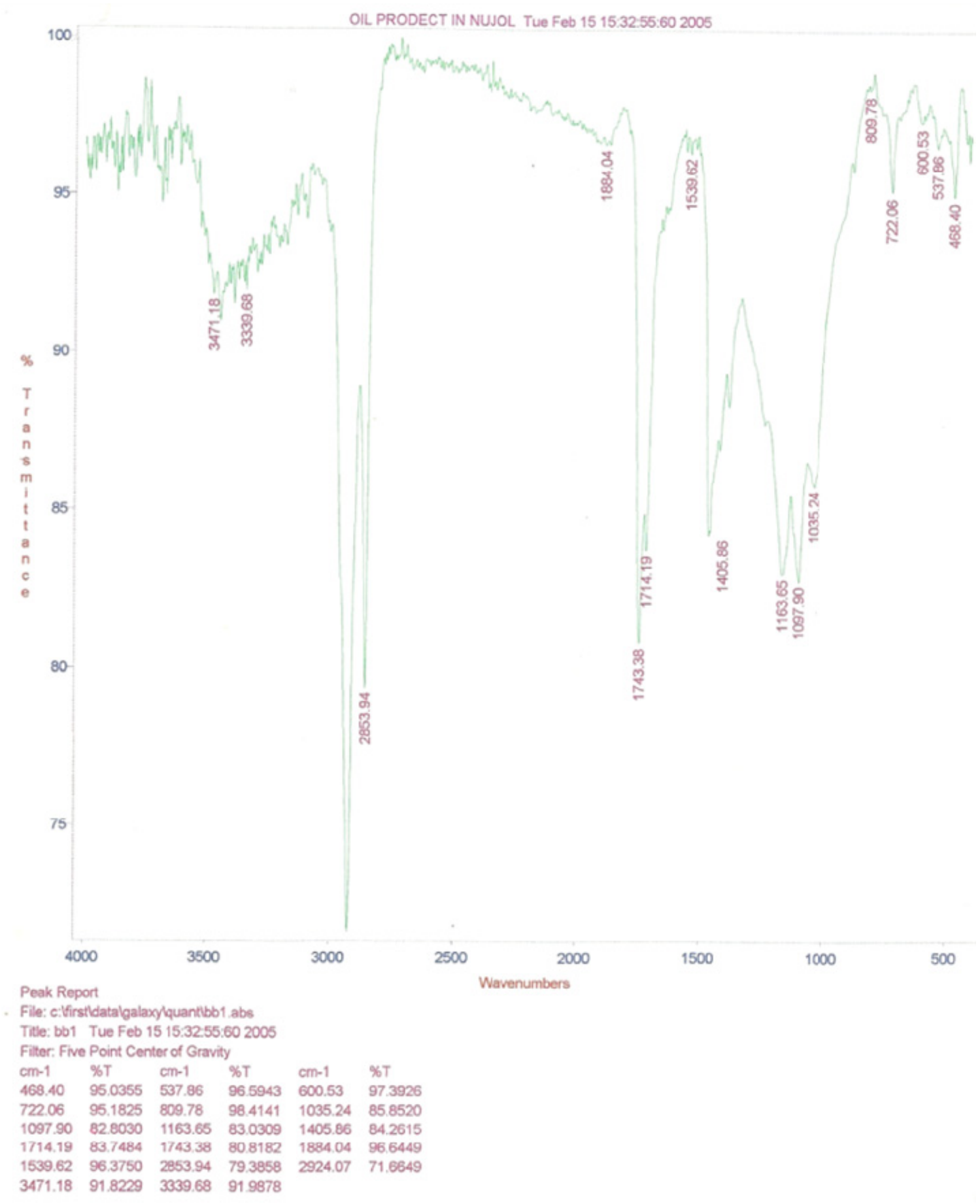

Figure 1. IR spectrum of sample 1

Plot of product weight/left over (unreacted) oil weight as a function of time (concentration/time curves) at various temperatures for the oil/ammonium chloride reaction show the temperature dependence of the reaction. Optimum reaction temperature was found to be $50{ }^{\circ} \mathrm{C}$ with a conversion of $89 \%$ and a product weight of $3.49 \mathrm{~g}$ at 60 minutes (Figure 2), beyond which the reaction attained equilibrium with reversal to starting material. Reversibility is uniquely displayed by the system as can be observed in the concentration/time curve (Figure 2). 


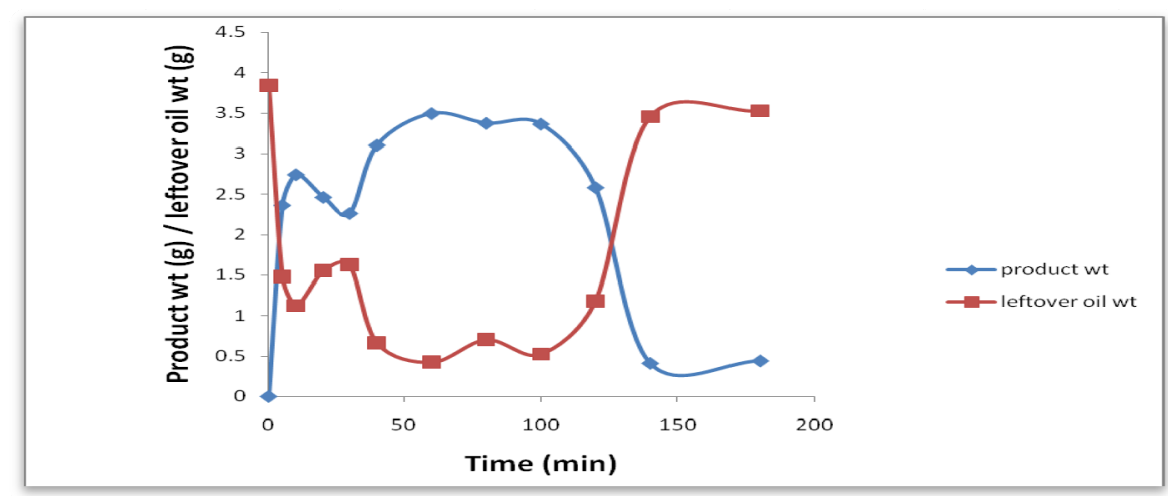

Figure 2. Plot of product wt/leftover oil wt against time at $50{ }^{\circ} \mathrm{C}$

Mass spectral/GC-FID peaks of Sample 1 obtained at various GC retention times are indicative of the presence of oleamide, ammonium oleate, ammonium linoleate, stearamide, palmitic and linoleic acid anhydrides, and mixed stearic/palmitic, linoleic/palmitic and oleic/palmitic anhydrides. All anhydride peaks are base-line; this is in consonance with literature which says that for anhydrides, molecular peaks are usually weak or absent (Kemp, 1987). A peak appearing at 299 in the mass spectrum of the product-12.03 min GC retention time coincides with the $\mathrm{M}+$ weight of the ammonium salt of oleic acid (ammonium oleate $-\mathrm{C}_{17} \mathrm{H}_{33} \mathrm{COOSNH}_{4}-299 \mathrm{~g}$ ) (Anyebe \& Ekpenyong, 2007). The GC-FID result showed ammonium oleate to have a peak area of $98 \%$ making it the major component of the product and this is as expected since oleic acid constitutes $60 \%$ of the fatty acids that make up groundnut oil.

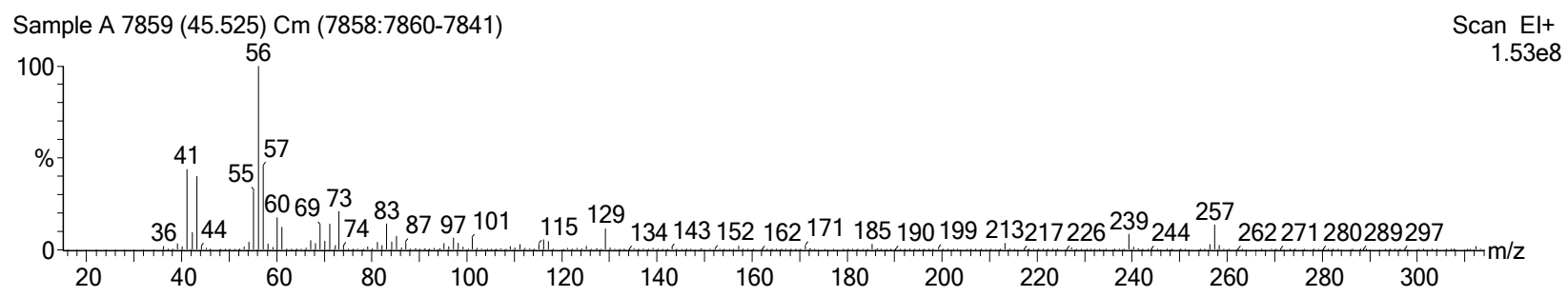

Figure 3. Mass spectrum of sample 1 which coincides with the molecular weight of ammonium linoleate (297)

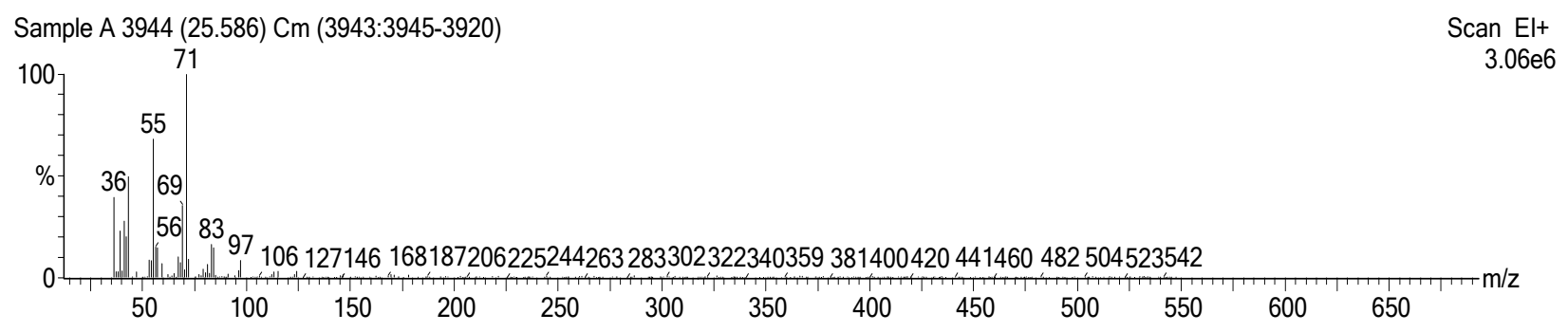

Figure 4. Mass spectrum of sample 1 which coincides with the molecular weight of linoleic acid anhydride (542)

Sample 2 exhibited peaks indicative of the presence of oleamide, methyl stearamide, oleic and linoleic acid anhydrides and oleic/linoleic, oleic/stearic and linoleic/stearic mixed anhydrides. The presence of methyl stearamide in this sample is significant, it is deduced that the methyl group is produced by methylamine. 
Print Date: 19 Jul 2005 10:28:26

\section{MS Data Review Active Chromatogram and Spectrum Plots - 7/19/2005 10:28 AM}

File: c:Ivarianwsldataliwunze_amine.sms Sample: Iwunze_amine

Scan Range: 1 - 1328 Time Range: $0.00-20.98 \mathrm{~min}$.

Operator: ellis benjamin

MCounts

Date: 6/27/2005 12:18 PM

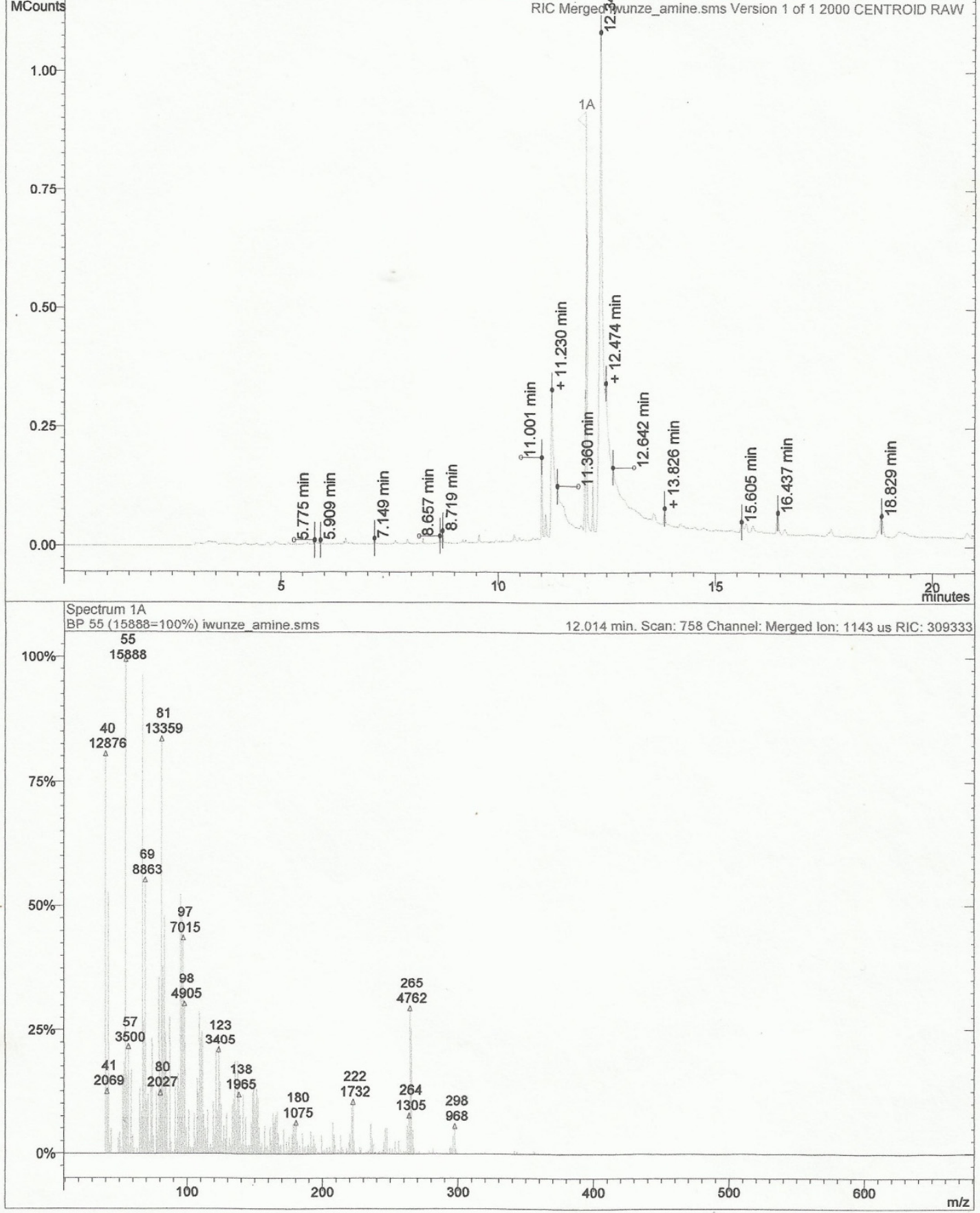

Figure 5. Mass spectrum of sample 2 which coincides with molecular weight of $(\mathrm{M}+1)$ ion peak of methyl stearamide- $\mathrm{C}_{17} \mathrm{H}_{35} \mathrm{CONHCH}_{3}$ (298)

The complexity of the system is revealed by the formation of several compounds, as indicated by the mass spectra of the product samples, few of which have been presented here. Conventional low molecular weight anhydrides, such as acetic acid anhydride, are well known and are stable compounds. Fatty acid anhydrides, 
however, are not so common and are rarely used, but their presence in the product samples must be an indication of their stability.

Simple as well as mixed fatty acid anhydrides have several applications. For example, they are reacted with glycerolphosphatidylcholine in the presence of pyridine as catalyst, in the production of phosphatidylcholine derivatives which have diverse uses. For example, dipalmitoylphosphatidylcholine is used as lung surfactant for improving breathing functions; dilinoleoylphosphatidylcholine is used for the treatment of lipid metabolism disturbances in the liver. Other phosphatidylcholine derivatives are excellent materials for pharmaceutical or cosmetic purposes as well as for the production of liposomes and phospholipid solutions (Schafer, 1994).

The ammonium salt of the fatty acids is known to be a precursor to the amide and these amides have a wide range of applications as earlier mentioned.

\section{Conclusion}

A fatty ester has been used directly in the production of fatty amide, hence one of the stages in the production of amides viz: first stripping the fatty ester to the fatty acid has been eliminated and these fatty esters are available in abundance.

The formation of the ammonium salts, amides and anhydrides of the fatty acids is practically confirmed. Fatty acid anhydrides, just as the fatty acid amides are commercially very significant and versatile; the ammonium salt is a precursor to the amide.

This is a low temperature reaction requiring a short reaction time of about 60 minutes, with a conversion as high as $89 \%$. The conditions used cannot be said to be harsh but rather optimal.

With these findings, a simple and definitely economic method of fatty amide and fatty acid anhydride production from fats and oils has been demonstrated.

Work is going on towards further characterization of the products and possible separation and purification of the numerous components.

\section{Acknowledgements}

We acknowledge the National Research Institute for Chemical Technology, Zaria, Nigeria for the IR spectrum of one of the ammonium salt samples.

Our gratitude goes to the Chemistry Department, Morgan State University, Maryland, USA, courtesy of Professor M. O. Iwunze, for the GC/MS analysis of some of the samples.

The Forest Products Department of the Mississippi State University, USA, is also acknowledged for the GC/MS analysis of some of the samples, courtesy of Dr. Anthonia Eseyin.

The National Agency for Food and Drug Administration and Control (NAFDAC), Nigeria is acknowledged for the GC-FID analysis of the samples, courtesy of Dr. Nelson Ochekpe.

\section{References}

Anonymous. (1999). Pain suppressors identified. Brown University News Services (BUNS), 11th October.

Anyebe, O. A., \& Ekpenyong, K. I. (2007). In Situ Fatty Ammonium Salt Formation in Sodium Hydroxide Hydrolysis of Groundnut Oil. European Journal of Scientific Research, 16(2), 474-476.

Christie, W. W. (2007a). Anandamide, Oleamide and Other Fatty Amides: Structure, Occurrence, Biology and Analysis. Retrieved from http://www.lipidlibrary.co.uk

Christie, W. W. (2007b). Mass Spectra of Methyl Esters of Fatty Acids: Part 2. Branched-Chain Fatty Acids. In Lipid Library. Retrieved from http://www.lipidlibrary.co.uk/ms/ms03a/index.htm

Hanus, L., Gopher, A., Almong, S., \& Mechoulam, R. (1993). Two New Unsaturated Fatty Acid Ethanolamides in Brain that Bind to the Cannabinoid Receptor. Journal of medicinal Chemistry, 36, 3032-3034. http://dx.doi.org/10.1021/jm00072a026

Holderness, A. (1970). Intermediate Organic Chemistry (2nd ed., p. 323). London: Heinemann Educational Books Ltd.

Kemp, W. (1987). Organic Spectroscopy (2nd ed., p. 299). Hampshire: English Language Book Society/Macmillan.

Kunos, G., Varga, K., Wagner, J., Ellis, E. F., \& Sanyai, A. (1999). Cardiovascular Uses of Cannabinoid Compounds. United states patent 5939429. http://dx.doi.org/10.1161/01.HYP.33.1.429 
Liberles, A. (1968). Introduction to Theoretical Organic Chemistry (p. 722). New York: The Macmillan Company.

National Agency for Food and Drug Administration (NAFDAC), Nigeria. (2007). AOAC Official Method 969.33 for Fatty Acids in Fats and Oils.

Nichols, K. K., Ham, B. M., Nichols, J. J., Ziegler, C., \& Green-Church, K. B. (2007). Identification of Fatty Acids and Fatty Acid Amides in Human Meibomian Gland Secretion. Journal of Investigative Ophthalmology and Visual Science, 48, 34-39. http://dx.doi.org/10.1167/iovs.06-0753

Oleamide. (2007). In Wikipedia, the free encyclopedia. Retrieved from http://www.en.wikipedia.org/wiki/oleamide

Ophardt, C. E. (2003). Lipids I, Fatty acids. Virtual chembookelmhurst college. Retrieved from http://www.elmhurst.edu/ chm/vchembook/551 fattyacids.html

Schafer, T. (1994). Process of Producing Phosphatidylcholine Derivatives. United States Patent 5321145. Retrieved from http://www.patentstorm.us/patents/5321145-description.html

Zradni, F. Z., Texier-Boullet, F., \& Hamelin, J. (2002). Synthesis of Amides from Esters and Amines under $\begin{array}{llll}\text { Microwave Irradiation. Synthetic } & \text { Communications, }\end{array}$ http://dx.doi.org/10.1081/SCC-120014792 